\title{
Dystrophin-glycoprotein complex and vinculin-talin-integrin system in human adult cardiac muscle
}

\author{
GIUSEPPE ANASTASI ${ }^{1}$, GIUSEPPINA CUTRONEO ${ }^{1}$, ROBERTO GAETA ${ }^{2}$, \\ DEBORA DI MAURO ${ }^{1}$, ALBA ARCO ${ }^{1}$, ANGELA CONSOLO ${ }^{1}$, \\ GIUSEPPE SANTORO $^{1}$, FABIO TRIMARCHI ${ }^{1}$ and ANGELO FAVALORO ${ }^{1}$ \\ Departments of ${ }^{1}$ Biomorphology and Biotechnologies, ${ }^{2}$ Clinical-Experimental \\ Medicine and Pharmacology, University of Messina, Messina, Italy
}

Received May 22, 2008; Accepted July 25, 2008

DOI: 10.3892/ijmm_00000112

\begin{abstract}
Costameres were identified, for the first time, in skeletal and cardiac muscle, as regions associated with the sarcolemma, consisting of densely clustered patches of vinculin; they have many characteristics common to the cellextracellular matrix-type of adherens junctions. Costameres are considered 'proteic machinery' and they appear to comprise two protein complexes, the dystrophin-glycoprotein complex (DGC) and the vinculin-talin-integrin system. In comparison to skeletal muscle, few studies have focused on cardiac muscle regarding these two complexes, and study is generally relative to dystrophin or to cardiac diseases, such as cardiomyopathies. However, insufficient data are available on these proteins in healthy human cardiomyocytes. For this reason, we performed an immunohistochemical study using human cardiac muscle fibers, in order to define the real distribution and the spatial relationship between the proteins in these two complexes. Our data showed a real costameric distribution of DGC and of the vinculin-talin-integrin system; all tested proteins were present in T-tubule and in intercalated disks. Moreover, our data demonstrated that all tested proteins of DGC colocalized with each other, as all tested components of the vinculin-talin-integrin system, and that all tested proteins of DGC colocalized with all tested proteins of the vinculin-talin-integrin system. Finally, all tested proteins of the two complexes were localized in the region of the sarcolemma over the I band, in $100 \%$ of our observations. The present study, for the first time, analyzed the majority of proteins of DGC and of the vinculin-talin-integrin system in cardiac muscle fibers, and it confirmed that DGC and the
\end{abstract}

Correspondence to: Dr Angelo Favaloro, Dipartimento di Biomorfologia e Biotecnologie, Università degli Studi di Messina, Policlinico Universitario 'G. Martino', Torre Biologica, Via Consolare Valeria 1, IT-98125 Messina, Italy

E-mail: angelo.favaloro@unime.it

Key words: cardiac muscle, costameres, T-tubules, intercalated disk, immunohistochemistry, atrium vinculin-talin-integrin system have a role in the transduction of mechanical force to the extracellular matrix. Finally it attributed a key role in the regulation of action potential duration to cardiac myocytes.

\section{Introduction}

Costameres were identified in skeletal and cardiac muscle, for the first time, by Pardo et al (1), as transverse lattice elements which marked sites of attachment between myofibrils and sarcolemma. Similar to the hoops and staves of a barrel, this cortical lattice has longitudinal elements and transverse circumferential elements. In skeletal muscle these elements have a substructure consisting of densely clustered patches of vinculin; the patches are segregated into two rows which flank the $\mathrm{Z}$ line and overlie the I band of the underlying sarcomere (1).

In cardiac muscle, the costameres appear somewhat different to those in skeletal muscle as cardiac costameres do not appear to consist of doublet bands flanking the $\mathrm{Z}$ line but instead appear as one band over it. They are generally narrower than the underlying I band with a greater staining intensity directly over the $\mathrm{Z}$ line (2).

It has become apparent that costameres have many characteristics common to the cell-extracellular matrix-type of adherens junction, in particular, the focal adhesion or adhesion plaque (3). Additionally, other proteins that are also involved in cytoskeletal-membrane interactions have been identified at sites coinciding with costameres (4-7). On this basis, it was demonstrated that costameres consist of cytoskeletal proteins that are associated with the sarcolemma (vinculin, talin and dystrophin), signaling proteins [nitric oxide synthase (NOS), syntrophins and dystrobrevin], transmembrane proteins (integrins, $\beta$-dystroglycan, and sarcoglycans), and extracellular proteins ( $\alpha$-dystroglycan and muscle agrin). Due to their constituents, costameres are considered as 'proteic machinery' and they appear to comprise two protein complexes that provide important signaling between the extracellular matrix and the muscle fibres: the dystrophin-glycoprotein complex (DGC) and the vinculintalin-integrin system (8-10).

The DGC, composed of at least ten proteins, links laminin 2 (merosin) of the extracellular matrix and actin and stabilizes 
the cell membrane during muscle activity $(11,12)$. Three subcomplexes can be identified in the context of DGC, on the basis of different biochemical characteristics and localization: the sarcoplasmic, the dystroglycan and the sarcoglycan transmembrane subcomplex.

Concerning the sarcoplasmic subcomplex, it was demonstrated that immunofluorescence changes occur in the $\mathrm{N}$-terminus region of dystrophin, in human failing myocardium (13). This alteration in dystrophin may be a final common pathway for contractile dysfunction resulting in dilated cardiomyopathy (14). The association of dystrophin with cardiomyocyte T-tubules, which play a key role in excitationcontraction coupling, suggests that dystrophin may serve diverse roles in myocyte membranes.

The dystroglycan subcomplex comprises $\alpha$ - and $\beta$ dystroglycan. $\alpha$-dystroglycan is an extracellular protein which binds to $\alpha$-laminin, a component of the basal lamina (extracellular matrix) and to ß-dystroglycan. ß-dystroglycan is a transmembrane glycoprotein that appears to play a fundamental role within the DGC complex, in connecting the intracellular cytoskeleton to the extracellular matrix, a function that does not appear to be limited to skeletal and cardiac muscles (9).

Sarcoglycan subcomplex is a multi-member complex closely associated with dystroglycan and is thought to stabilize the interactions of dystroglycan with the extracellular matrix and with dystrophin and its associated proteins (15). Six sarcoglycan genes have been identified to date, $\alpha-, \beta-, \gamma^{-}, \delta-$, $\varepsilon^{-}$, and $\zeta$-sarcoglycan, organized in a tetrameric arrangement (16). In particular, the composition of the sarcoglycan subcomplex, in skeletal and cardiac muscle, is represented by

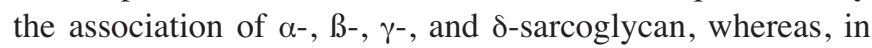
smooth muscle, it is represented by $\varepsilon^{-}, \beta_{-}, \delta_{-}$, and $\xi$-sarcoglycan (17). Our recent reports on smooth muscle, hypothesized that the six sarcoglycans can be arranged in an exameric structure $(18,19)$.

Regarding the vinculin-talin-integrin system, it is commonly known that vinculin and talin are cytoskeletal proteins which are believed to be essential components in the linkage of cytoskeletal actin filaments to the plasma membrane (20). Integrins are heterodimers composed of an $\alpha$ and a $\beta$ subunit (21). The cytoplasmic domain is relatively short but nevertheless can participate in an intracellular signaling cascade (22). At present, 22 heterodimers have been identified, composed of $16 \alpha$ chains and $8 \beta$ chains. The $\alpha 7 \mathrm{~B}$ and $\beta 1 \mathrm{D}$ isoforms are the most common integrins found in adult skeletal muscle $(23,24)$. In particular, they mediate the processes of cell adhesion and migration and regulate the intracellular organization of the actin cytoskeleton; they also play an important role in many signaling processes (21).

Talin and integrin $\beta 1$ are known to show striated distribution patterns similar to costameres in cardiac muscle $(23,24)$, suggesting that these proteins may help form the adhesion complex with vinculin at the costameres, mediating contraction force transmission.

In comparison to skeletal muscle, relatively few studies have focused on cardiac muscle regarding the behaviour of DGC and the vinculin-talin-integrin complex in the costameres $(25,26)$, and the majority of these is relative to dystrophin. In particular, it was demonstrated in rat cardiac muscle, that dystrophin is not uniquely distributed at costameres and is continuously and uniformly distributed at the cytoplasmic surface of the peripheral plasma membrane (27). Conversely, other authors demonstrated that dystrophin partially colocalizes with costameric vinculin in healthy myocytes, suggesting a primarily mechanical role for dystrophin in the maintenance of cell membrane integrity (28).

It was demonstrated that intracellular regions of cardiac muscle revealed a selective labeling of Z-disks by dystrophin antibodies suggesting that this protein may play a key role in maintaining structural integrity of cardiac muscle (26). Finally, it was well documented that, in addition to the sarcolemma, a substantial pool of dystrophin also localizes at the T-tubules in cardiac muscle in contrast to its known absence in skeletal muscle T-tubules (29), implying additional roles of dystrophin in the membrane domain (28). Concerning the sarcoglycans subcomplex, previous studies have addressed the behaviour in pathological muscle and specifically muscular dystrophy, sarcoglycanopathies or cardiomyopathies (30-32), and insufficient data are available on these proteins in healthy human cardiomyocytes.

Accordingly, the present study set out to apply highresolution single- and double-immunolabeling techniques in order to define, in human cardiac muscle fibers, the real distribution and the precise spatial relationship between the proteins of DGC and of the vinculin-talin-integrin system in relation to the costameres, the T-tubule, and the intercalated disks.

\section{Materials and methods}

Samples of healthy human adult cardiac muscle were obtained from 5 male patients who underwent surgery for valvulopathy. Patients were between 40 and 60 years of age. All patients gave informed consent and all procedures followed were in accordance with the principles outlined in the Helsinki Declaration of 1975.

Biopsies, obtained from the left atrium were fixed in $3 \%$ paraformaldehyde in a $0.2 \mathrm{M}$ phosphate buffer at $\mathrm{pH} 7.4$, for $2 \mathrm{~h}$. After numerous rinses in $0.2 \mathrm{M}$ phosphate buffer and phosphate-buffered saline (PBS), the biopsies were infiltrated with saccharose at 12 and $18 \%$, to obtain a gradual substitution of saline solution with glucosate solution and then to avoid disruption of cellular membranes during successive phases. Finally the sections were frozen in liquid nitrogen.

Sections $(20 \mu \mathrm{m})$ were cut on a cryostat and collected on glass slides coated with $0.5 \%$ gelatin and $0.005 \%$ chromium potassium sulphate. To block non-specific sites and to render the membranes permeable, sections were pre-incubated with $1 \%$ BSA and $0.3 \%$ Triton X-100 in PBS at room temperature for $15 \mathrm{~min}$. Finally, sections were incubated with primary antibodies for $2 \mathrm{~h}$. Different series of single and double localizations were performed. Antibodies used and their dilutions are listed in Table I.

In all reactions, TRITC-conjugated $\mathrm{IgG}$ anti-mouse in goat was used as first fluorochrome (1:100 dilution; Jackson ImmunoResearch Laboratories, West Grove, PA) and applied for $1 \mathrm{~h}$ with the primary antibody.

For double-localization reactions, after many rinses with PBS and incubation with a biotinylated $\mathrm{IgG}$ in goat to obtain 
Table I. Antibodies, sources and dilutions used.

Primary antibodies

Source

Dilution

DGC complex

Anti- $\alpha$-sarcoglycan (monoclonal mouse)

Anti-ß-sarcoglycan (monoclonal mouse)

Anti- $\gamma$-sarcoglycan (monoclonal mouse)

Anti- $\delta$-sarcoglycan (monoclonal mouse)

Anti- $\varepsilon$-sarcoglycan (monoclonal mouse)

Anti-ß-dystroglycan (monoclonal mouse)

Anti-dystrophin $\mathrm{COOH}$-terminus (monoclonal mouse)

Novocastra Laboratories Ltd

Novocastra Laboratories Ltd

Novocastra Laboratories Ltd

$1: 100$

Novocastra Laboratories Ltd

$1: 50$

Novocastra Laboratories Ltd

$1: 100$

Novocastra Laboratories Ltd

$1: 100$

Novocastra Laboratories Ltd

Vinculin-talin-integrin system

Anti-vinculin (monoclonal mouse)

Sigma-Aldrich

$1: 100$

Anti-talin (monoclonal mouse)

Sigma-Aldrich

$1: 100$

Anti- $\alpha 7 \mathrm{~B}$ integrin (polyclonal mouse)

Laboratories of Prof Tarone

$1: 50$

Anti-ß31D integrin (polyclonal mouse)

Laboratories of Prof Tarone

$1: 50$

Secondary antibodies

Source

Dilution

IgG anti mouse in goat conjugated with TRITC

IgG anti rabbit in donkey conjugated with TRITC

Anti-F-actin conjugated with FITC

Jackson ImmunoResearch Laboratories Inc.

$1: 100$

Jackson ImmunoResearch Laboratories Inc. $\quad 1: 100$

Jackson ImmunoResearch Laboratories Inc. $\quad 1: 100$

saturation of the residual-free binding sites, sections were incubated with a second antibody conjugated with FITCconjugated secondary IgG, as second fluorochrome (1:100 dilution; Jackson ImmunoResearch Laboratories).

Slides were finally washed in PBS and sealed with mounting medium. Sections were then observed and photographed using a Zeiss LSM 5 Duo laser scanning microscope (Carl Zeiss; Jena, Germany). All images were digitalized at a resolution of 8 bits into an array of 2048 x 2048 pixels. Optical sections of fluorescence specimens were obtained using a $\mathrm{HeNe}$ laser $(543 \mathrm{~nm})$ and an $\operatorname{argon}$ laser $(458 \mathrm{~nm})$ at a 1-min, 2 -sec scanning speed with up to 8 averages; $1.5-\mu \mathrm{m}$ sections were obtained using a pinhole of 250 . For each reaction, a minimum of 100 fibers was observed, in order to obtain a statistical analysis.

Contrast and brightness were established by examining the most brightly labeled pixels and applying settings that allowed clear visualization of structural details while keeping the highest pixel intensities close to 200. The same settings were used for all images obtained from the other samples that had been processed in parallel.

Digital images were cropped and figure montages prepared using Adobe Photoshop 7.0 (Adobe Systems; Palo Alto, CA).

\section{Results}

In order to define a targeting model of the real distribution of DGC and vinculin-talin-integrin system proteins, we analyzed all proteins with single- and double-immunolabeling techniques, in healthy human adult atrial muscle.

Using confocal laser scanning microscopic observations, we studied the immunostaining of all known sarcoglycans, Bdystroglycan and dystrophin, and of any proteins of the vinculin-talin-integrin system, in longitudinal and in transverse sections, using specific antibodies.

We performed a negative control on a longitudinal section of normal human adult atrial muscle, using only the secondary antibody (Fig. 1A); in Fig. 1B, we showed the corresponding transmitted light of Fig. 1A.

Immunoconfocal microscopy revealed consistent costameric patterns of all sarcoglycans and B-dystroglycan in longitudinal (Fig. 2A-F) and in transverse sections (data not shown). The analysis of dystrophin in transverse sections (Fig. 2G), showed a punctuate pattern that evidenced a costameric distribution of this protein, similar to the longitudinal section (data not shown).

Indirect immunofluorescence applied in healthy human adult atrial muscle, using antibodies against vinculin-talinintegrin system, showed a similar costameric distribution in longitudinal and transverse sections. We demonstrated the costameric pattern of $\alpha 7 \mathrm{~B}$-integrin (Fig. 3A) and talin (Fig. 3D), in longitudinal sections, and of $\beta 1 \mathrm{D}$-integrin (Fig. 3B) and vinculin (Fig. 3C) in transverse sections.

In order to investigate the presence of proteins in T-tubules and intercalated disks, we applied the single localization reactions in transverse and longitudinal sections of healthy human adult atrial muscle, respectively. In all observations, we consistantly detected the immunofluorescence pattern for all tested proteins. Regarding T-tubules, the immunofluorescence of $\alpha$-sarcoglycan (Fig. 4A), $\varepsilon$-sarcoglycan (Fig. 4B), Bdystroglycan (Fig. 4C), dystrophin (Fig. 4D), vinculin (Fig. 4E), and $\alpha 7 \mathrm{~B}$-integrin (Fig. 4F), comprising $\beta-, \gamma-, \delta$-sarcoglycan, B1D-integrin and talin (not shown); a thin layer at myocyte sarcolemma, with irregular spoke-like extensions, penetrating toward the center of the cell (yellow arrows), clearly indicated the presence of these proteins in T-tubules. Observations of 

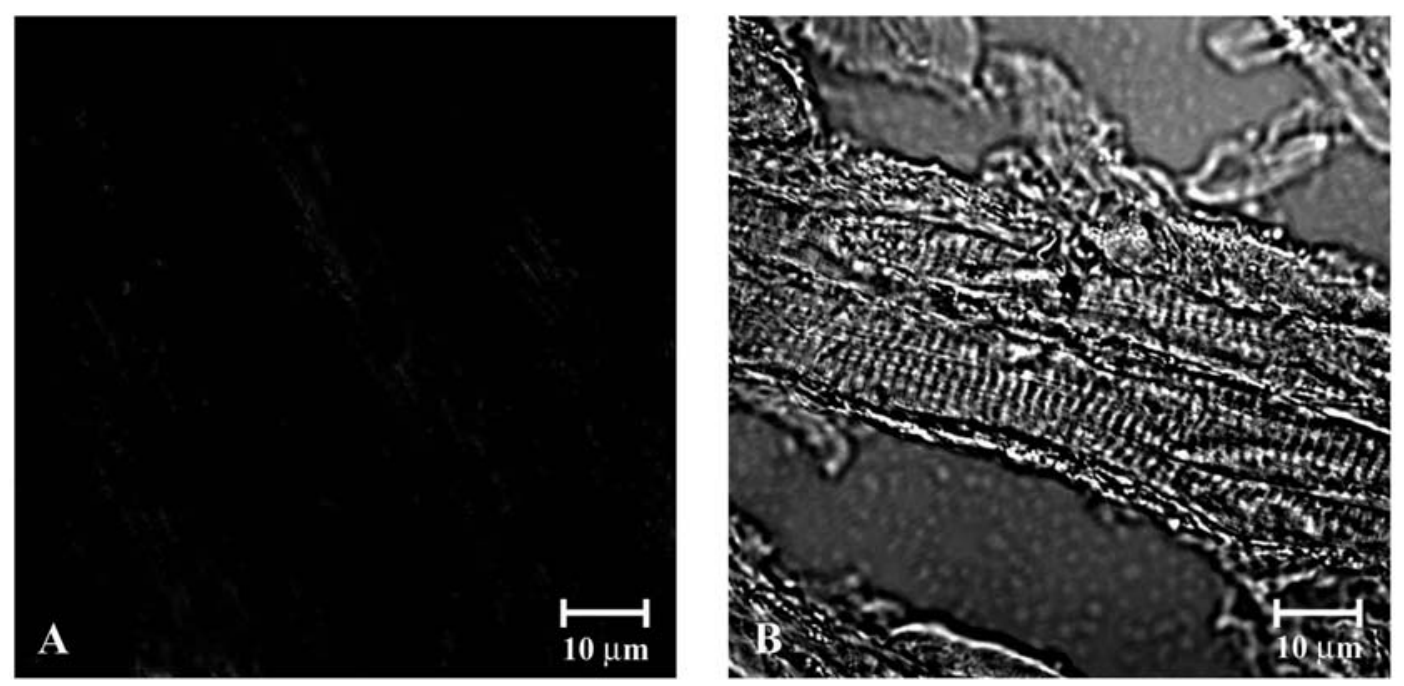

Figure 1. Negative control of a longitudinal section of normal human adult atrial myocardium immunolabeled with the secondary antibody only (A), and corresponding transmitted light (B).
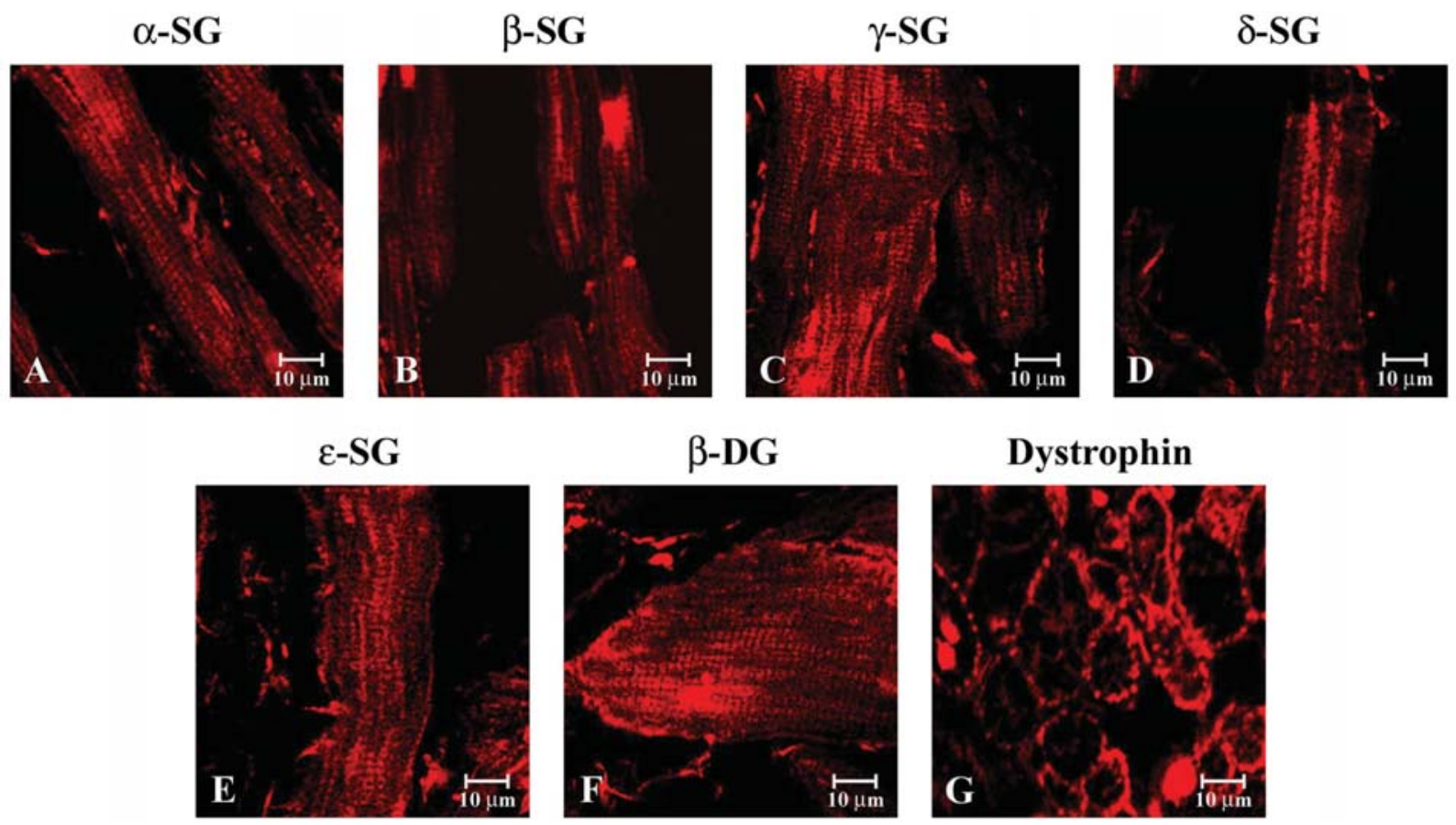

Figure 2. Normal human adult atrial myocardium labeled for $\alpha$-sarcoglycan (A); $\beta$-sarcoglycan (B); $\gamma$-sarcoglycan (C); $\delta$-sarcoglycan (D); $\varepsilon$-sarcoglycan $(\mathrm{E}) ; \beta$-dystroglycan $(\mathrm{F})$ and dystrophin $(\mathrm{G})$. In longitudinal sections all tested proteins of DGC appeared as costameric bands at regular intervals (A-F). In transverse sections, dystrophin showed a precisely matched punctuate pattern observed at peripheral sarcolemma (G).

longitudinal sections labeled with single localization evidenced the presence of proteins in intercalated disks, showing a clearly detectable staining pattern. All tested DGC proteins (Fig. 4G-J), comprising $\beta_{-}^{-}, \gamma^{-}$, and $\varepsilon$-sarcoglycan (not shown), and all vinculin-talin-integrin system proteins (Fig. 4K-L), including vinculin and $\alpha 7 \mathrm{~B}$-integrin (not shown), were visualized as bright and clear labeled in the thick pattern that indicates the intercalated disks of cardiac fibers (yellow arrows).

To better test the contemporary presence of all proteins, in longitudinal and transverse sections, and their localization, we performed two stocks of double-localization reactions.
The first stock was carried out by matching antibodies to all DGC-tested proteins with themselves, antibodies to all vinculin-talin-integrin system proteins with themselves, and finally antibodies to all proteins of DGC with antibodies to all proteins of vinculin-talin-integrin system. The second stock was carried out matching antibodies to all proteins of two complexes with antibodies to sarcomeric actin (localized to the I-band).

In the first set of immunofluorescent images, a clear yellow fluorescence in the longitudinal and transverse sections revealed the contemporary presence, and then the colocalization, of $\alpha$-sarcoglycan with $\gamma$-sarcoglycan (Fig. 5A), of $\beta$-sarcoglycan 


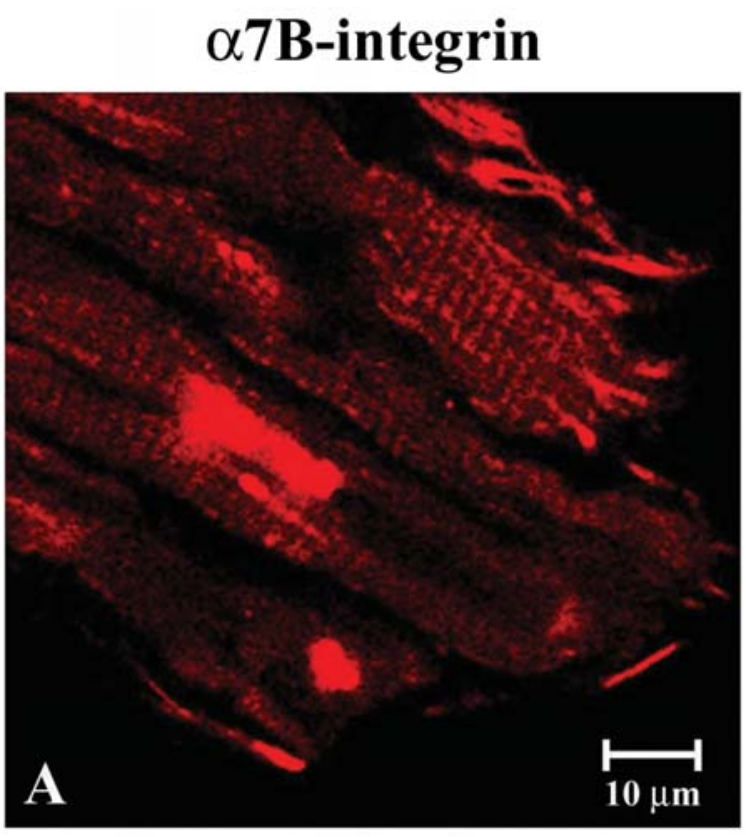

\section{Vinculin}

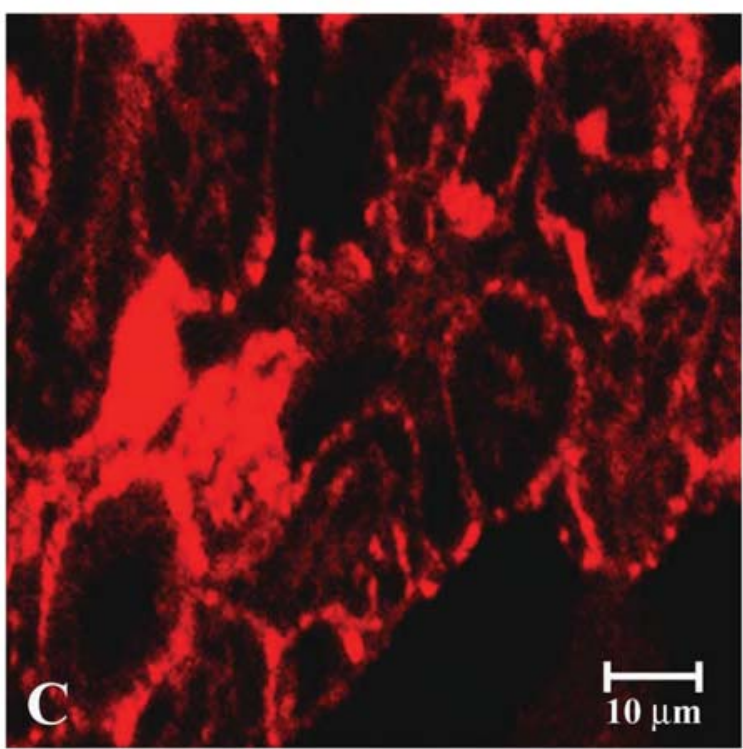

$\beta 1 D$-integrin

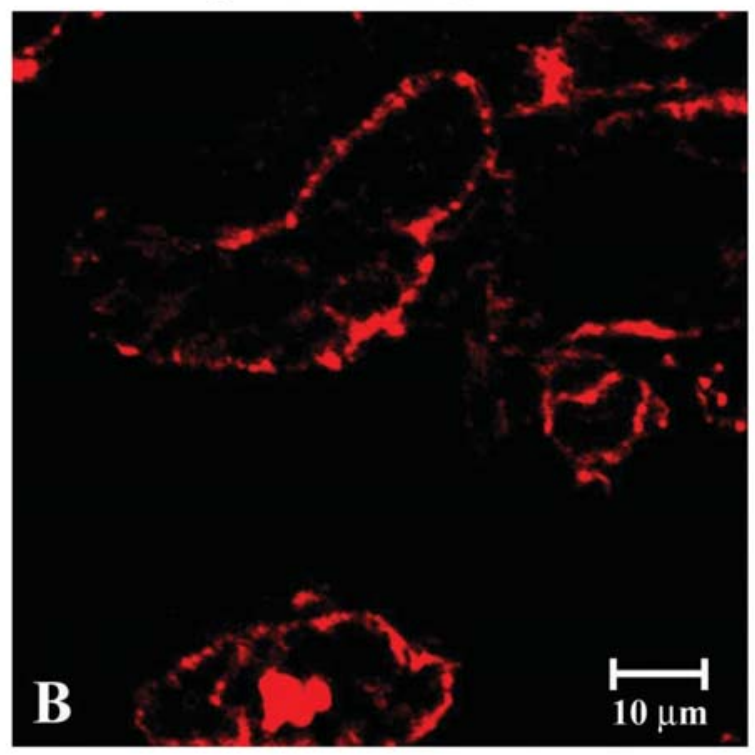

Talin

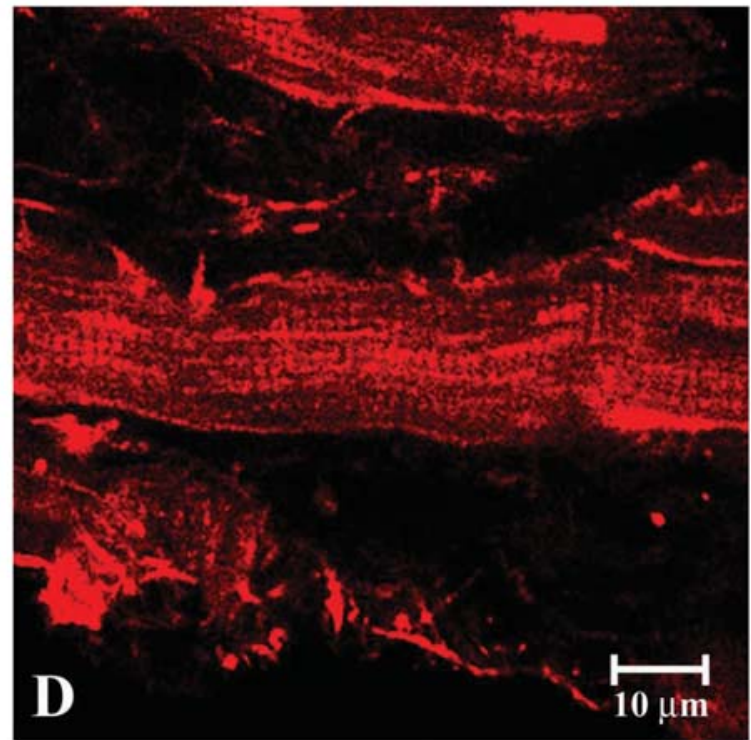

Figure 3. Normal human adult atrial myocardium labeled for $\alpha 7 \mathrm{~B}$-integrin (A); ß1D-integrin (B); vinculin (C) and talin (D). These proteins, in longitudinal (A and $\mathrm{D})$ and transverse (B and $\mathrm{C})$ sections also showed a costameric distribution mirroring that of DGC proteins.

with dystrophin (Fig. 5B), of $\gamma$-sarcoglycan with B-dystroglycan (Fig. 5C), and of ß-dystroglycan with dystrophin (Fig. 5D). The yellow signal of immunofluorescence revealed the superimposition of the red and green channel. The same colocalization staining pattern was detectable in other reactions (not shown).

Similar colocalization patterns were detectable with vinculin-talin-integrin system proteins. The yellow signal of all images revealed a colocalization of $\alpha 7 \mathrm{~B}$-integrin with $\beta 1 \mathrm{D}$ integrin (Fig. 5E), of $\alpha 7 \mathrm{~B}$-integrin with vinculin (Fig. 5F), of B1D-integrin with talin (Fig. 5G), and vinculin with talin (Fig. 5H). The same colocalization staining pattern was detectable in the other reactions (not shown).
Similar conditions were detectable for double localization reactions carried-out when matching antibodies for DGC proteins with antibodies for the vinculin-talin-integrin system. The yellow signal of each reaction revealed a colocalization of $\alpha$-sarcoglycan with $\alpha 7 \mathrm{~B}$-integrin (Fig. 6A), of ß-sarcoglycan with B1D-integrin (Fig. 6B), of dystrophin with vinculin (Fig. 6C), and of B-dystroglycan with talin (Fig. 6D), in sarcolemma and in intercalated disks (blue arrows). The same colocalization staining pattern was detectable in the other reactions (not shown).

In the second set of immunofluorescent reactions we matched all proteins of two complexes with sarcomeric actin. We observed that all proteins constantly colocalized with 


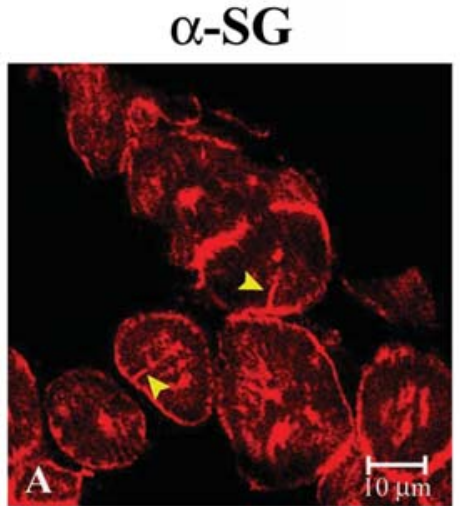

Dystrophin

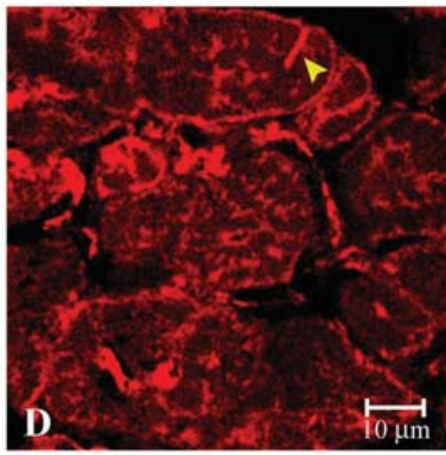

$\alpha-S G$

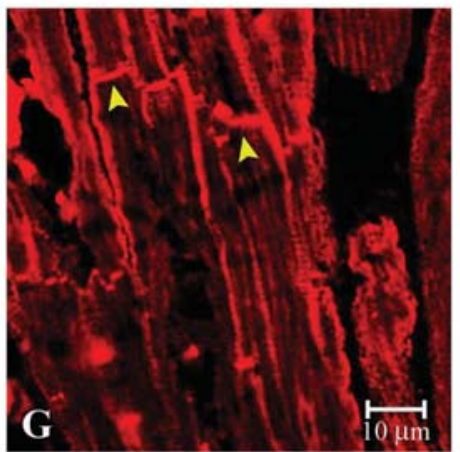

Dystrophin

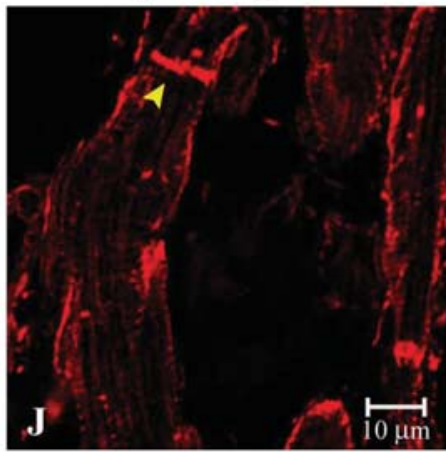

$\varepsilon-S G$

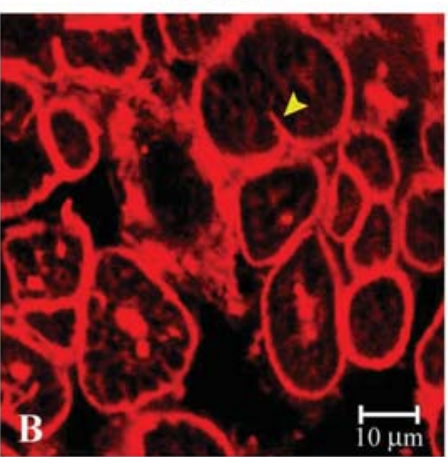

Vinculin

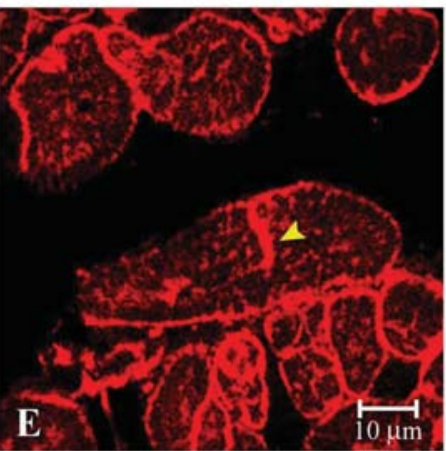

$\delta$-SG

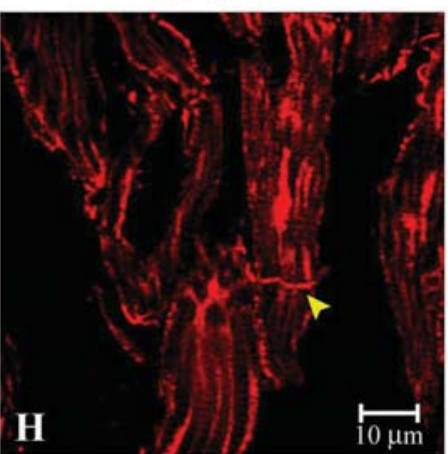

Talin

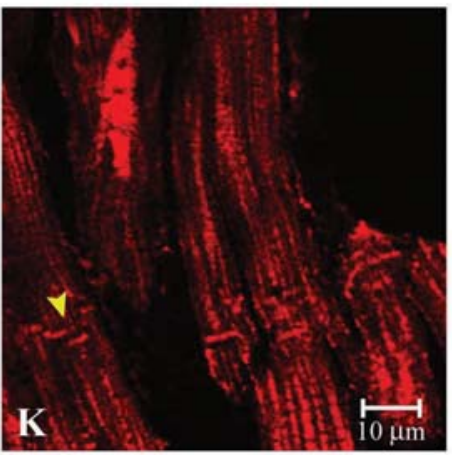

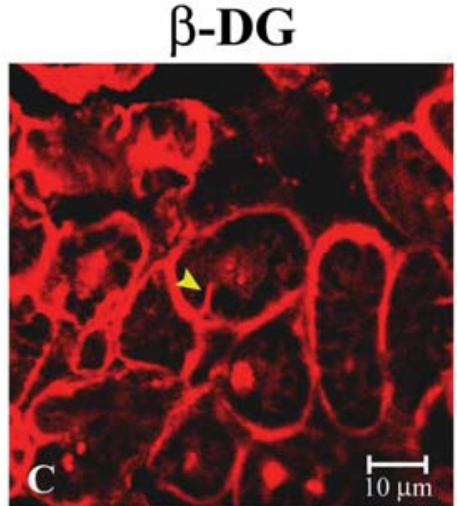

$\alpha 7 \mathrm{~B}$-integrin

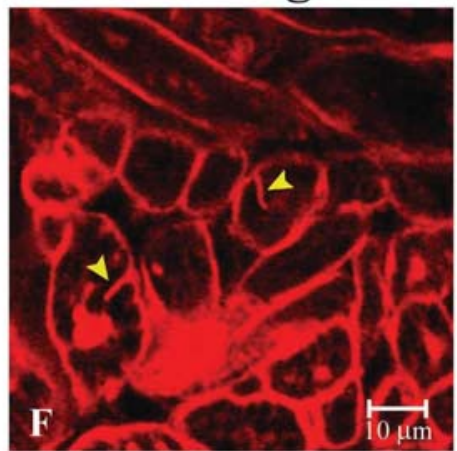

$\beta-D G$

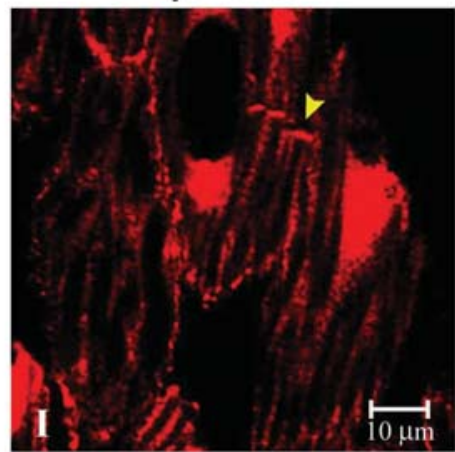

$\beta 1 D$-integrin

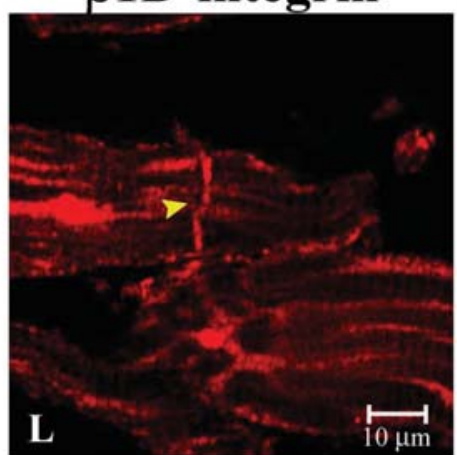

Figure 4. Transverse sections of normal human adult atrial myocardium, labeled (upper panel) for $\alpha$-sarcoglycan (A); $\varepsilon$-sarcoglycan (B); $\beta$-dystroglycan (C); dystrophin (D); vinculin (E) and $\alpha 7 \mathrm{~B}$-integrin (F). In all sections, T-tubules (yellow arrows) were clearly detectable and observed oriented transverse to long axis of cells. In the lower panel, the longitudinal sections of normal human adult atrial myocardium labeled for $\alpha$-sarcoglycan (G); $\delta$-sarcoglycan (H); $\beta$-dystroglycan (I); dystrophin (J); talin (K) and B1D-integrin (L). In all sections, intercalated disks (yellow arrows) were evident.

actin, evident by the yellow signal due to the superimposition of the red and green channel. This indicated that $\alpha$-sarcoglycan (Fig. 7A), $\gamma$-sarcoglycan (Fig. 7B), B-dystroglycan (Fig. 7C), dystrophin (Fig. 7D), a7B-integrin (Fig. 7E), vinculin (Fig. 7F), and all other proteins (not shown), were consistantly localized on the regions of the sarcolemma corresponding to the I-band. 

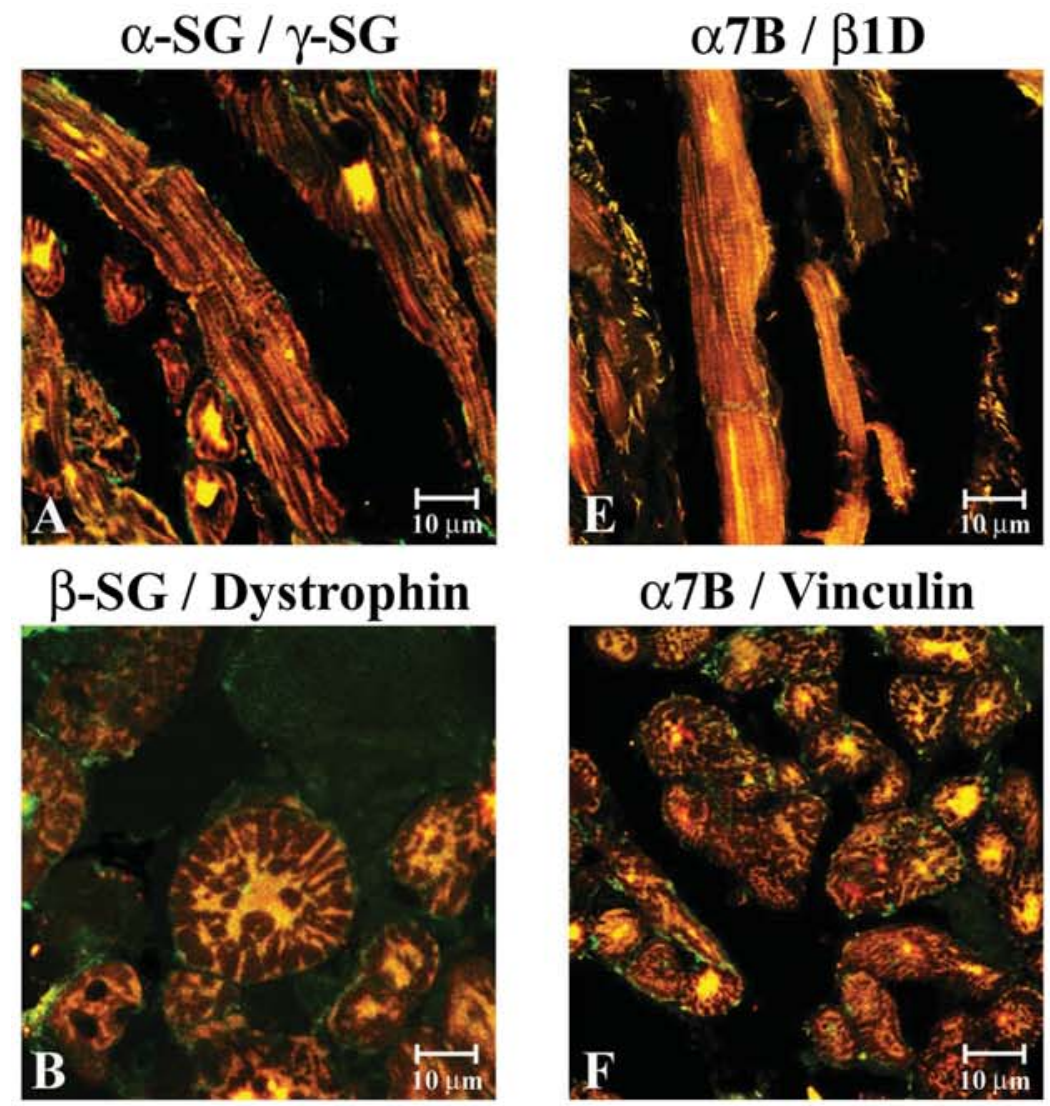

\section{$\alpha 7 \mathrm{~B}$ / Vinculin}
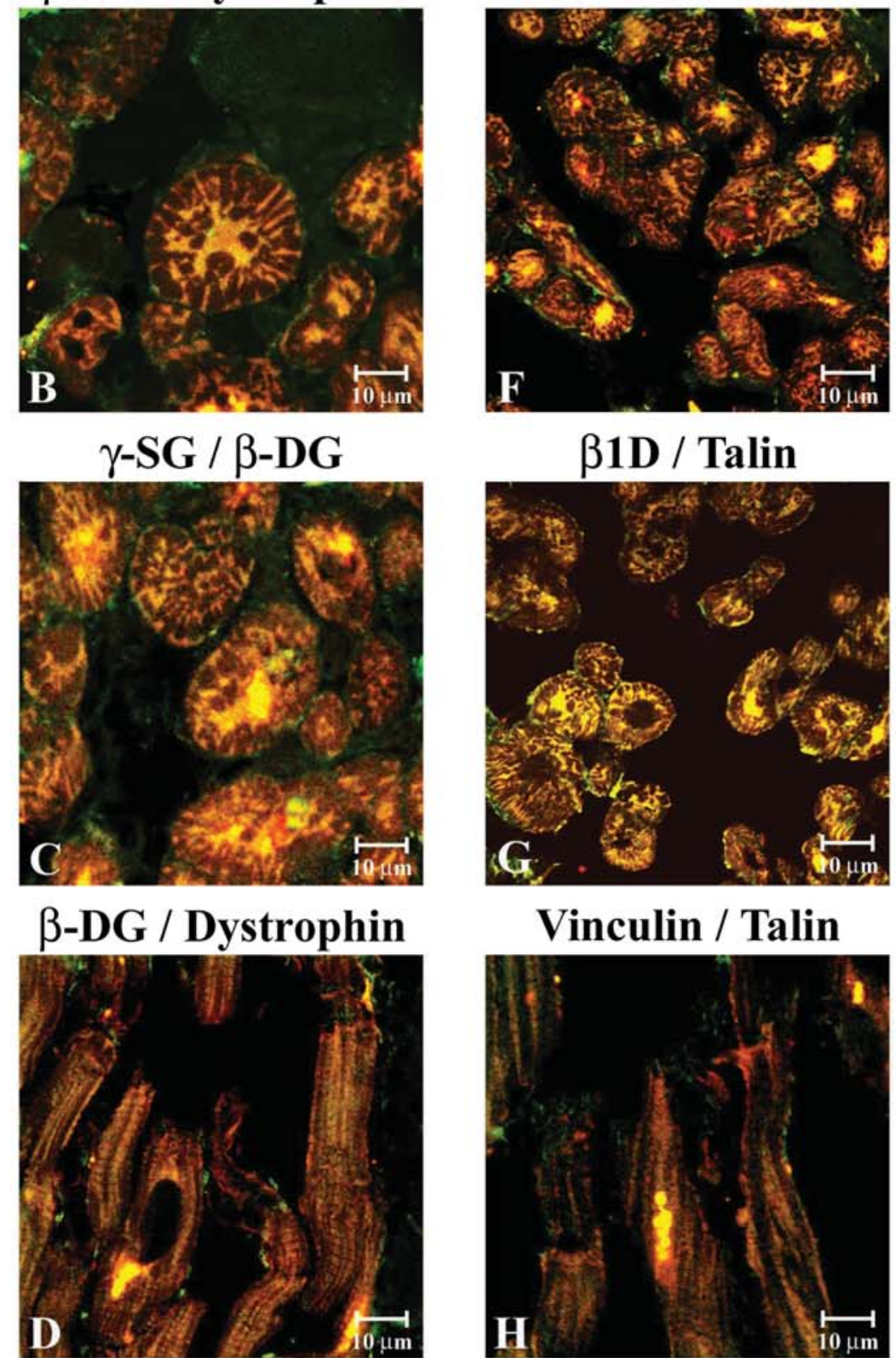

Figure 5. In the left panel, normal human adult atrial myocardium double-labeled for $\alpha$ - $/ \gamma$-sarcoglycan (A); $\beta$-sarcoglycan $/$ dystrophin (B); $\gamma$-sarcoglycan/ $\beta$ dystroglycan (C) and B-dystroglycan/dystrophin (D). In longitudinal (A and D) and in transverse (B and C) sections, all proteins of DGC colocalize with each other of the same complex. In the right panel, normal human adult atrial myocardium double-labeled for $\alpha 7 \mathrm{~B}-/ B 1 \mathrm{D}$-integrin (E); $\alpha 7 \mathrm{~B}$-integrin/vinculin (F); B1D-integrin/talin $(\mathrm{G})$ and vinculin/talin $(\mathrm{H})$. In all reactions the first protein is indicated with red fluorescence, the second protein is indicated with green fluorescence and areas of colocalization are presented as a yellow pattern. For proteins of the vinculin-talin-integrin system, all proteins colocalize with each other in longitudinal $(\mathrm{E}$ and $\mathrm{H})$, and in transverse sections ( $\mathrm{F}$ and $\mathrm{G})$. 


\section{$\alpha-S G$ / $\alpha$ 7B-integrin}

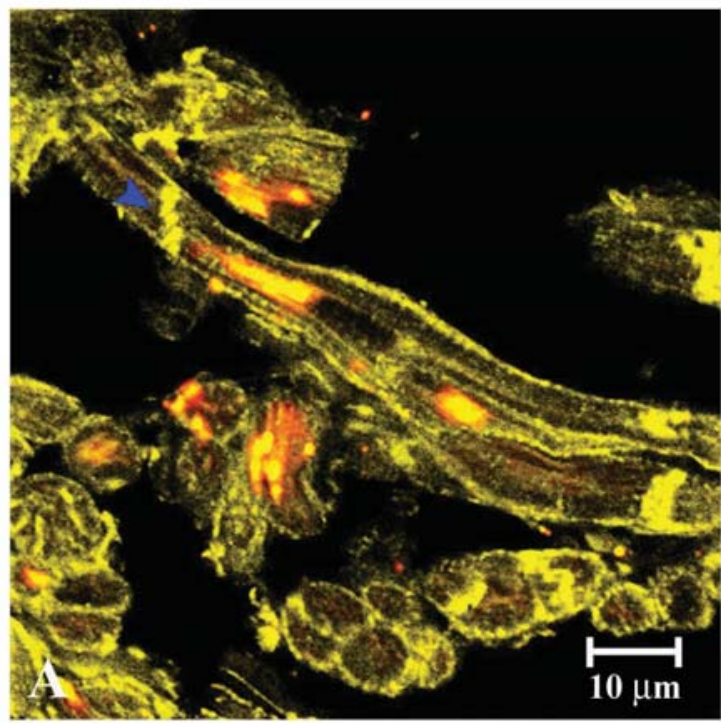

Dystrophin / Vinculin

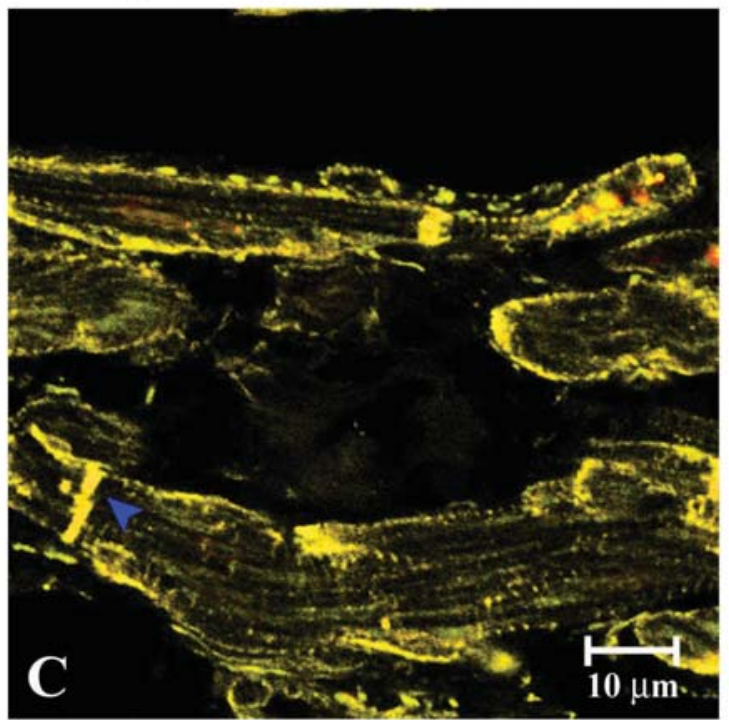

$\beta-S G$ / $\beta 1 D$-integrin

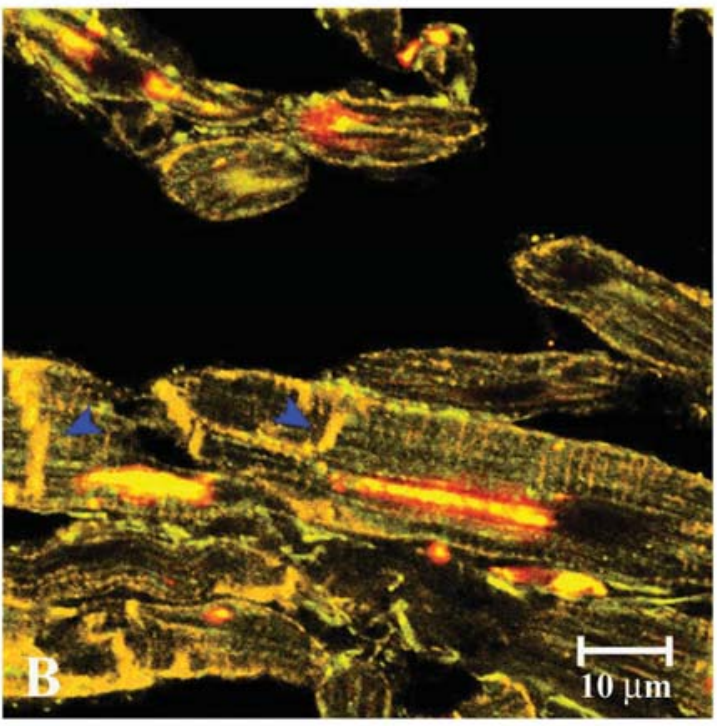

$\beta$-DG / Talin

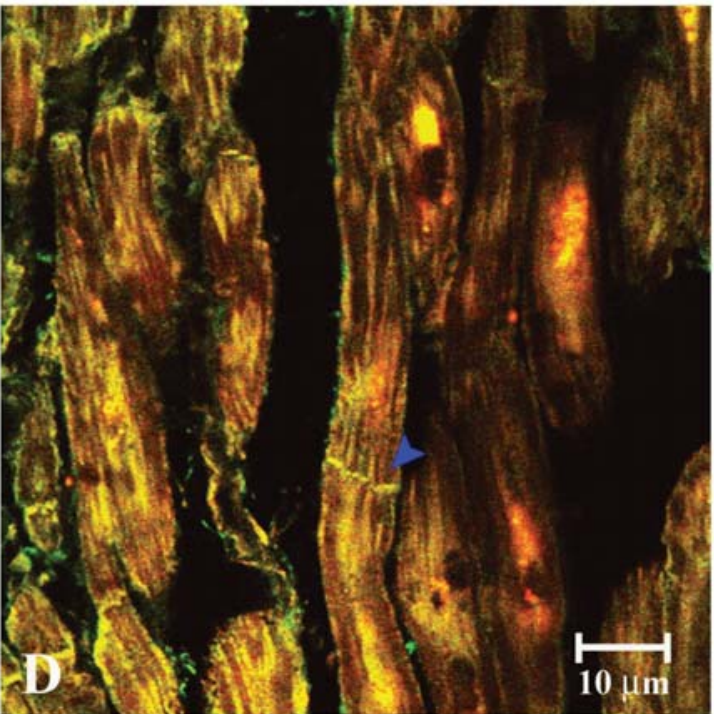

Figure 6. Normal human adult atrial myocardium double-labeled for $\alpha$-sarcoglycan/ $\alpha$ B-integrin (A); $\beta$-sarcoglycan/ $\beta 1 D$-integrin (B); dystrophin/vinculin (C) and B-dystroglycan/talin (D). In all reactions the first protein is indicated with red fluorescence and the second with green fluorescence. All images show a constant colocalization of DGC proteins with the vinculin-talin-integrin system proteins, in sarcolemma and in intercalated disks (blue arrows). Areas of colocalization are seen as a yellow staining pattern.

\section{Discussion}

In the present investigation, we applied a single- and a simultaneous dual-channel scanning immunoconfocal microscope, to study the distribution and localization of the components of DGC and the vinculin-talin-integrins system in healthy human cardiac muscle fibers.

The original purpose of our study was to investigate whether two complexes showed costameric distribution and the same behaviour of localization as reported in human skeletal muscle (33), and to investigate the presence of these proteins in intercalated disks and in the T-tubule.

The novel results of the present study showed, for the first time, a) a real costameric distribution of all tested proteins of DGC, including dystrophin, and of all tested proteins belonging to the vinculin-talin-integrin system; b) the presence of all tested proteins in the T-tubule and c), in intercalated disks. Moreover, in double-immunofluoresence reactions, our data showed that all tested proteins of DGC colocalized between each other, as all tested components of the vinculin-talinintegrins system, in $100 \%$ of observations. All tested proteins of DGC constantly colocalized with all tested proteins of the vinculin-talin-integrin system and all tested proteins of two complexes were localized in the region of the sarcolemma over the I band, in $100 \%$ of observations.

The present study, for the first time, analyzed the majority of proteins of DGC and of the vinculin-talin-integrin system in cardiac muscle fibers; all these proteins constantly showed a costameric distribution. Additionally, our results, showing the colocalization of all proteins with each other and the 
$\alpha-S G$ / Actin

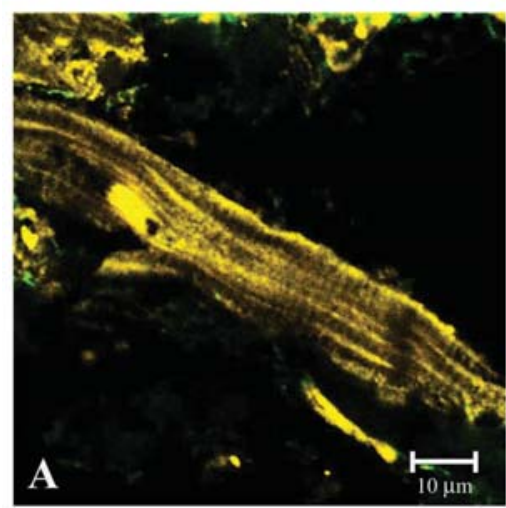

Dystrophin / Actin

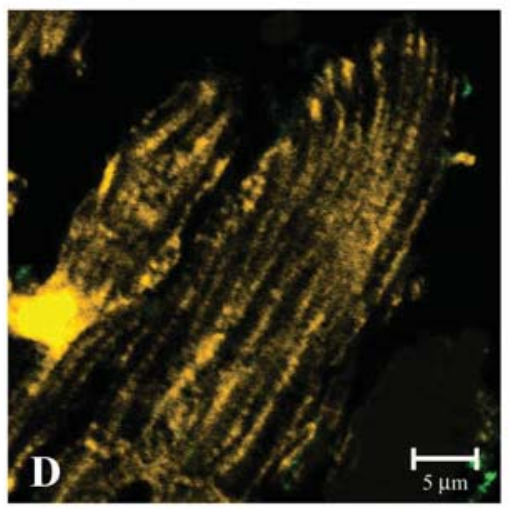

$\gamma$-SG / Actin

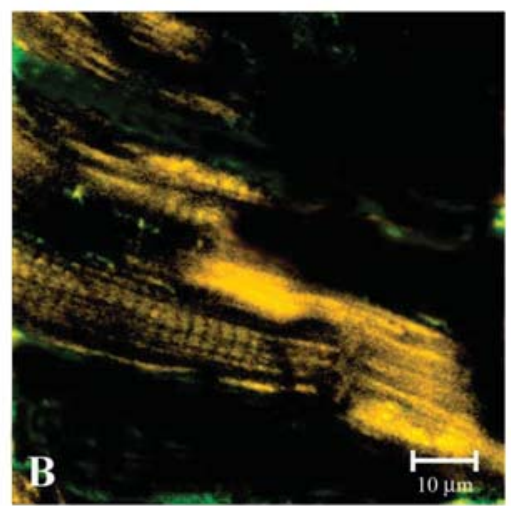

$\alpha 7 \mathbf{B} /$ Actin

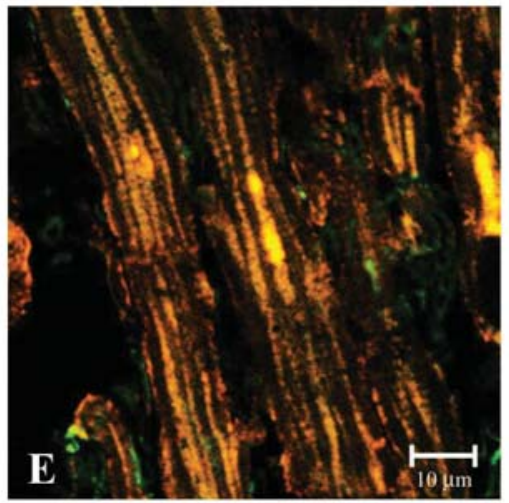

$\beta$-DG / Actin

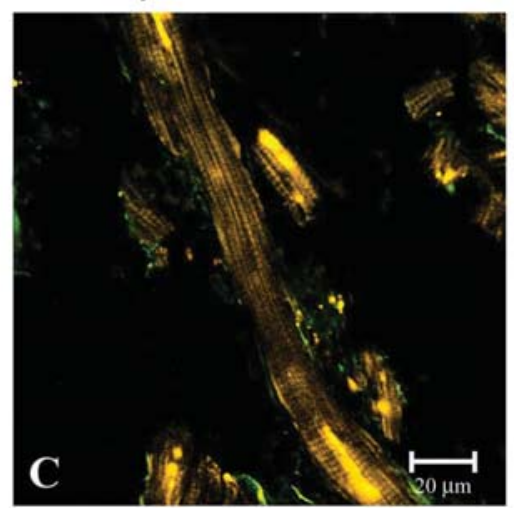

Vinculin / Actin

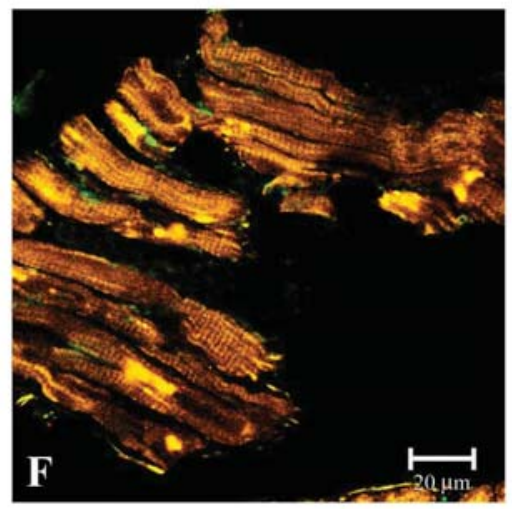

Figure 7. Normal human adult atrial myocardium double-labeled for $\alpha$-sarcoglycan/actin (A); $\gamma$-sarcoglycan/actin (B); $\beta$-dystroglycan/actin (C); dystrophin/actin (D); $\alpha$-7B-integrin/actin (E) and vinculin/actin (F). In all reactions, the first protein is indicated with red fluorescence and the second, with green fluorescence. All images constantly show a colocalization of all tested proteins with sarcomeric actin, indicating that all proteins are localized on the regions of the sarcolemma corresponding to the I-band.

localization of all proteins in the region over the I band, confirm, first, that a protein machinery exists in cardiac, as well as in skeletal muscle (10) and secondly, confirm our previous hypothesis on the localization of sarcoglycans in human skeletal and cardiac muscle (34).

Previously we demonstrated that a different distribution of sarcoglycans exists in the two muscles types. By using double-immunolabeling techniques between sarcoglycans and sarcomeric actin, we demonstrated that sarcoglycans, in skeletal muscle can be localized, in distinct fibers, in regions of the sarcolemma over the I band or over the A band. Conversely, in cardiac muscle, sarcoglycans were localized constantly in the regions of the sarcolemma over the I band. In obtaining these results, we hypothesized a correlation between regions of the sarcolemma occupied by costameres and the metabolic types of the fibers (fast or slow). In particular the slow fibers are characterized by the localization of costameric proteins in the region of the sarcolemma over the I band and the fast fibers by the localization of the costameres in the region over the A band (34).

It is commonly known, regarding mammalian skeletal muscle that the current consensus of immunofluorescence studies is that dystrophin, and other associated proteins, have a non-uniform distribution at the cytoplasmic surface of the plasma membrane. These are in the form of dense transversely oriented bands at the I band level, at costameres, linked by finer longitudinally oriented strands (35-38). In mouse cardiac muscle, early studies suggested a continuous subsarcolemmal layer of dystrophin, hypothesizing that dystrophin is not a specific component of the cardiac costameres (27). Our present observations clearly indicate that dystrophin, and other associated proteins, constantly presented a costameric distribution. We propose that the differences in the dystrophin distributions could be due to different tissues being analyzed. Our observations were carried out on human cardiac muscle, while other studies have used a SpragueDawley rat (27) or mouse muscle (25). On this basis, it is clear that subtle but distinct differences exist between human and rat cardiomyocytes. Human myocytes show concentrated bands at the sites of the vinculin-rich costameres, while in rat myocytes, dystrophin presented as a continuous sheet, indicating the existence of species differences in cardiac dystrophin distribution between large and small animals.

Therefore, it is possible to attribute the mechanical role represented by the maintenance of membrane stability (28) to the membrane-associated dystrophin protein complex. The membrane cytoskeleton thus has the potential to contribute to the mechanical strength of the muscle surface membrane involving stabilization of the peripheral plasma membrane during the repetitive distortions associated with cardiac contraction. The continuous pattern of dystrophin demonstrated in rat cardiomyocytes suggests a uniform strengthening 
over the entire expanse of the peripheral plasma membrane $(25,27)$.

In this way, the human heart, being larger and generating a higher wall shear stress according to Laplace's law, may display a clustering of dystrophin over the costameric regions of the membrane and points of highest force, as an adaptation to provide the necessary increase in mechanical strength. This hypothesis is supported by the evidence that the higher stress to which human skeletal muscle is exposed, due to the greater body mass, may therefore be important regarding myocyte damage in Duchenne muscular dystrophy (35). Therefore, the concentration of dystrophin over the costameric regions of the human cardiac fibers may be important for the adaptation to provide increased mechanical strength of the myocyte membrane at these points.

The presence of all tested proteins in intercalated disks of human cardiac muscle, suggests, for dystrophin and other proteins, a role in transduction of mechanical force to the extracellular matrix. The integrins are also involved in this function. They play an essential role in the maintenance of the bidirectional communication of mechanical force between cardiomyocyte cytoskeleton and the extracellular matrix (39). The mechanical forces are transduced into biochemical signals leading to sarcomeric assembly and altered gene expression. This form of signaling is the predominant mechanism responsible for adaptive growth of cardiomyocytes in response to changing hemodynamic loads (40). We suggest that the presence of these proteins in intercalated disks implies a functional role in cell-to-cell interaction.

Our data, showing the presence of the vinculin-talinintegrin system in intercalated disks, demonstrate that these adhesion proteins play a key role in order to form a complete mechanical linkage, extending from the myofibrils to the plasma membrane, across the plasma membrane and to the extracellular matrix. Furthermore, these data also support results of other studies which showed that the transmission of contraction forces at the costameres of cardiomyocytes to the silicone rubber substrata is inhibited by the addition of an antibody which interferes with the ligand binding of $\beta 1$ integrin. This provides strong evidence that this protein has a role in mediating the transmission of contraction forces of cardiomyocytes (41). It has been reported that integrins as well as cadherin have important functions in the signal transduction pathway in cell sorting of myofibrillogenesis of cardiomyocytes (42).

Previously, in mouse cardiac muscle it was shown that the dystrophin is absent in the T-tubules (25). Our present results also showed the presence of all tested proteins at cardiomyocyte T-tubules implying an additional role of dystrophin and its associated proteins. The T-tubules, though critical to excitation-contraction coupling, are not directly involved in the transmission of contractile force and are not implicated during myocyte contraction. The absence of dystrophin from skeletal muscle T-tubules, distinguished from those of cardiomyocytes by the absence of a basement membrane, and the different mechanisms of excitation-contraction coupling in skeletal and cardiac muscle, provide the evidence that the dystrophin in cardiac muscle, together with other membrane proteins, plays a key role in membrane regulation. Dystrophin demonstrated a regulatory effect on calcium transport by altering the gating properties of AChRs in recent single channel patch clamp studies (43). In addition, dystrophin has been shown to have a key role in the regulation of the activity of other proteins such as membrane nitric oxide synthase (44) and caveolin (45). It has been demonstrated that T-tubules are a key site for the regulation of action-potential duration in cardiac myocytes, and mainly in atrial cardiac myocytes (46).

Finally, our results that show the constant presence of all sarcoglycans, including $\varepsilon$-sarcoglycan, and the colocalization of sarcoglycans with dystrophin and other proteins, confirm our previous data obtained on smooth muscle regarding their exameric arrangement $(18,19)$. They are in contrast with other studies which demonstrated, in bovine and old $\mathrm{mdx}$ mouse, that dystrophin is exclusively associated with $\beta$ dystroglycan and $\alpha$ - and $\delta$-sarcoglycan and is not associated with $\beta$ - and $\gamma$-sarcoglycan (47). These researchers hypothesized that two different dystrophin isoforms exist that do not have the same properties and distribution in cardiac muscle, but we propose that a comparative analysis on human cardiac muscle would be useful.

The findings of this work highlight the importance of costameric proteins in human cardiac muscle fibers and the potential key role of further and more detailed investigation of these proteins related with other proteins, as regulatory kinases. Further investigation may better define the precise role of costameres in mechanotransduction and in growth factor signaling during the continuing cycles of contraction and relaxation of human cardiac muscle. We also suggest that further investigation is necessary to precisely define the differences between atrial and ventricular muscle fibers.

\section{References}

1. Pardo JV, D'Angelo Siliciano J and Craig SW: A vinculincontaining cortical lattice in skeletal muscle: transverse lattice elements ('costameres') mark sites of attachment between myofibrils and sarcolemma. Proc Natl Acad Sci USA 80: 1008-1012, 1983

2. Pardo JV, D'Angelo Siliciano J and Craig SW: Vinculin is a component of an extensive network of myofibril-sarcolemma attachment regions in cardiac muscle fibers. J Cell Biol 97: 1081-1088, 1983.

3. Burridge $\mathrm{K}$ and Chrzanowska-Wodnicka $\mathrm{M}$ : Focal adhesions, contractility and signaling. Annu Rev Cell Dev Biol 12: 463-518, 1996.

4. Lazarides E: The distribution of desmin (100 ̊) filaments in primary cultures of embryonic chick cardiac cells. Exp Cell Res 112: 265-273, 1978.

5. Repasky EA, Granger BL and Lazarides E: Widespread occurrence of avian spectrin in non-erythroid cells. Cell 29: 821-833, 1982 .

6. Craig SW and Pardo V: Gamma-actin, spectrin, and intermediate filament proteins colocalize with vinculin at costameres, myofibril-to-sarcolemmal attachment sites. Cell Motil 3: 449-462, 1983.

7. Belkin AM, Zhidkova NI and Koteliansky VE: Localization of talin in skeletal and cardiac muscle. FEBS Lett 200: 32-36, 1986.

8. Danowsky BA, Imanaka-Yoshida K, Sanger JM and Sanger JW: Costameres are sites of force transmission to the substratum in adult rat cardiomyocytes. J Cell Biol 118: 1411-1420, 1992.

9. Ervasti JM and Campbell KP: A role for the dystrophinglycoprotein complex as a transmembrane linker between laminin and actin. J Cell Biol 122: 809-823, 1993.

10. Mondello MR, Bramanti P, Cutroneo G, Santoro G, Di Mauro D and Anastasi G: Immunolocalization of the costameres in human skeletal muscle fibers: confocal scanning laser microscope investigations. Anat Rec 245: 481-487, 1996. 
11. Yoshida M and Ozawa E: Glycoprotein complex anchoring dystrophin to sarcolemma. J Biochem 108: 748-752, 1990.

12. Ervasti JM and Campbell KP: Membrane organization of the dystrophin-glycoprotein complex. Cell 66: 1121-1131, 1991.

13. Fabbrizio E, Bonet-Kerrache A, Leger JJ and Mornet D: Actindystrophin interface. Biochemistry 32: 10457-10463, 1993.

14. Towbin JA: The role of cytoskeletal proteins in cardiomyopathies. Curr Opin Cell Biol 10: 131-139, 1998.

15. Hack AA, Groh ME and McNally EM: Sarcoglycans in muscular dystrophy. Microsc Res Tech 48: 167-180, 2000.

16. Wheeler MT, Zarnegar S and McNally EM: Z-sarcoglycan, a novel component of the sarcoglycan complex, is reduced in muscular dystrophy. Hum Mol Genet 11: 2147-2154, 2002.

17. Wheeler MT and McNally EM: Sarcoglycans in vascular smooth and striated muscle. Trends Cardiovasc Med 13: 238-243, 2003.

18. Anastasi G, Cutroneo G, Sidoti A, et al: Sarcoglycan subcomplex in normal human smooth muscle: an immunohistochemical and molecular study. Int J Mol Med 16: 367-374, 2005.

19. Anastasi G, Cutroneo G, Sidoti A, et al: Sarcoglycan subcomplex expression in normal human smooth muscle. J Histochem Cytochem 55: 831-843, 2007.

20. Schwartz MA: Transmembrane signaling by integrins. Trends Cell Biol 2: 304-308, 1992.

21. Hynes RO: Integrins: versatility, modulation, and signaling in cell adhesion. Cell 69: 11-25, 1992.

22. Schwartz MA, Schaller MD and Ginsberg MH: Integrins: emerging paradigms of signal transduction. Annu Rev Cell Dev Biol 11: 549-599, 1995.

23. Belkin AM, Zhidkova NI, Balzac F, et al: $\beta 1 \mathrm{D}$ integrin displaces the $\beta 1 \mathrm{~A}$ isoform in striated muscle: localization at junctional structures and signaling potential in nonmuscle cells. J Cell Biol 132: 211-226, 1996.

24. Belkin AM, Retta SF, Pletjushkina OY, et al: Muscle B1D integrin reinforces the cytoskeleton-matrix link: modulation of integrin adhesive function by alternative splicing. J Cell Biol 139: 1583-1595, 1997

25. Byers TJ, Kunkel LM and Watkins SC: The subcellular distribution of dystrophin in mouse skeletal, cardiac and smooth muscle. J Cell Biol 115: 411-421, 1991.

26. Meng H, Leddy JJ, Franki J, Holland P and Tuana BS: The association of cardiac dystrophin with myofibrils/Z-disc regions in cardiac muscle suggests a novel role in the contractile apparatus. J Biol Chem 271: 12364-12371, 1996.

27. Stevenson S, Rothery S, Cullen MJ and Severs NJ: Dystrophin is not a specific component of the cardiac costamere. Circ Res 80: 269-280, 1997.

28. Kaprielian RR and Severs NJ: Dystrophin and the cardiomyocyte membrane cytoskeleton in the healthy and failing heart. Heart Fail Rev 5: 221-238, 2000.

29. Klietsch R, Ervasti JM, Arnold W, Campbell KP and Jorgensen AO: Dystrophin-glycoprotein complex and laminin colocalize to the sarcolemma and transverse tubules of cardiac muscle. Circ Res 72: 349-360, 1993.

30. Noguchi S, McNally EM, Ben K, et al: Mutations in the dystrophin-associated protein $\gamma$-sarcoglycan in chromosome 13 muscular dystrophy. Science 270: 819-822, 1995.

31. Lim LE, Duclos F, Broux O, et al: $\gamma$-sarcoglycan: characterization and role in limb-girdle muscular dystrophy linked to 4q12. Nat Genet 11: 257-265, 1995.
32. Honda T, Sugiyama S, Sakamoto T, Kaikita K and Ogawa H: Impact of delta-sarcoglycan gene polymorphism on the occurrence of coronary spastic angina in Japanese patients with hypertrophic cardiomyopathy. Circ J 71: 1263-1267, 2007.

33. Anastasi G, Amato A, Tarone G, et al: Distribution and localization of vinculin-talin-integrin system and dystrophinglycoprotein complex in human skeletal muscle. Cells Tissues Organs 175: 151-164, 2003.

34. Anastasi G, Cutroneo G, Trimarchi F, et al: Sarcoglycans in human skeletal muscle and human cardiac muscle: a confocal laser scanning microscope study. Cells Tissues Organs 173: 54-63, 2003.

35. Masuda T, Fujimaki N, Ozawa E and Ishikawa H: Confocal laser microscopy of dystrophin localization in guinea pig skeletal muscle fibers. J Cell Biol 119: 543-548, 1992

36. Minetti C, Beltrame F, Marcenaro G and Bonilla E: Dystrophin at the plasma membrane of human fibres shows a costameric localisation. Neuromuscul Disord 2: 99-109, 1992.

37. Porter GA, Dmytrenko GM, Winkelmann JC and Bloch RJ: Dystrophin colocalizes with beta-spectrin in distinct subsarcolemmal domains in mammalian skeletal muscle. J Cell Biol 117: 997-1005, 1992 .

38. Straub V, Bittner RE, Léger JJ and Voit T: Direct visualization of the dystrophin network on skeletal muscle fiber membrane. J Cell Biol 119: 1183-1191, 1992.

39. Sussman MA, McCulloch A and Borg TK: Dance band on the Titanic: biomechanical signaling in cardiac hypertrophy. Circ Res 91: 888-898, 2002.

40. Samarel AM: Costameres, focal adhesions, and cardiomyocyte mechanotransduction. Am J Physiol Heart Circ Physiol 289: H2291-H2301, 2005.

41. Imanaka-Yoshida K, Enomoto-Iwamoto M, Yoshida T and Sakakura T: Vinculin, Talin, Integrin alpha6beta1 and laminin can serve as components of attachment complex mediating contraction force transmission from cardiomyocytes to extracellular matrix. Cell Motil Cytoskeleton 421: 1-11, 1999.

42. Imanaka-Yoshida K: Myofibrillogenesis in precardiac mesoderm explant culture. Cell Struct Funct 22: 45-49, 1997.

43. Carlson CG and Officer T: Single channel evidence for a cytoskeletal defect involving acetylcholine receptors and calcium influx in cultured dystrophic (mdx) myotubes. Muscle Nerve 19: 1116-1126, 1996.

44. Chang WJ, Iannaccone ST, Lau KS, et al: Neuronal nitric oxide synthase and dystrophin-deficient muscular dystrophy. Proc Natl Acad Sci USA 93: 9142-9147, 1996.

45. Song KS, Scherer PE, Tang Z, et al: Expression of caveolin-3 in skeletal cardiac and smooth muscle cells: Caveolin-3 is a component of the sarcolemma and co-fractionates with dystrophin and dystrophin associated glycoproteins. J Biol Chem 271: 15150-15165, 1996.

46. Brette F, Sallè L and Orchard H: Quantification of calcium entry at the T-tubules and surface membrane in rat ventricular myocytes. Biophys J 90: 381-389, 2006.

47. Rivier F, Robert A, Royuela M, Hugon G, Bonet-Kerrache A and Mornet D: Utrophin and dystrophin-associated glycoproteins in normal and dystrophin deficient cardiac muscle. J Muscle Res Cell Motil 20: 305-314, 1999. 